\title{
An open source toolkit for 3D printed fluidics
}

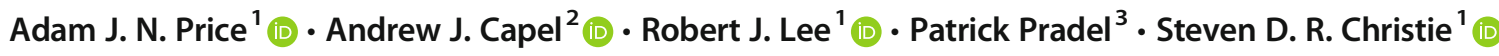

Received: 14 August 2020 / Accepted: 16 September 2020 / Published online: 15 October 2020

(C) The Author(s) 2020, corrected publication November 2020

\begin{abstract}
As 3D printing technologies become more accessible, chemists are beginning to design and develop their own bespoke printable devices particularly applied to the field of flow chemistry. Designing functional flow components can often be a lengthy and laborious process requiring complex 3D modelling and multiple design iterations. In this work, we present an easy to follow design workflow for minimising the complexity of this design optimization process. The workflow follows the development of a 3D printable 'toolkit' of common fittings and connectors required for constructing basic flow chemistry configurations. The toolkit components consist of male threaded nuts, junction connectors and a Luer adapter. The files have themselves been made freely available and open source. The low cost associated with the toolkit may encourage educators to incorporate flow chemistry practical work into their syllabus such that students may be introduced to the principles of flow chemistry earlier on in their education and furthermore, may develop an early appreciation of the benefits of 3D printing in scientific research. In addition to the printable toolkit, the use of the 3D modelling platform - Rhino3D has been demonstrated for its application in fluidic reactor chip design modification. The simple user interface of the programme reduces the complexity and workload involved in printable fluidic reactor design.
\end{abstract}

Keywords 3D printing $\cdot$ Additive manufacturing $\cdot$ Flow chemistry $\cdot$ Fluidics $\cdot$ Open source

\section{Introduction}

Increased accessibility to affordable 3D printing equipment, as well as a broader acceptance of $3 \mathrm{D}$ printing within

The original version of this article has been revised: The missing Electronic supplementary file named $<$ RhinoDemo3.mp4 $>$ has been added.

\section{Article Highlights}

- We show how to design and prepare a full set of interconnections suitable for preparation of a chemistry flow kit

- We provide, free to download and use, a a full set of printable files for these interconnections

-We show, and provide free to use, a simple technique for generation of printable flow chips

Electronic supplementary material The online version of this article (https://doi.org/10.1007/s41981-020-00117-2) contains supplementary material, which is available to authorized users.

Steven D. R. Christie

s.d.christie@lboro.ac.uk

1 School of Science, Loughborough University, Loughborough LE11 3TU, UK

2 School of Sport, Exercise and Health Sciences, Loughborough University, Loughborough LE11 3TU, UK

3 Design School, Loughborough University, Loughborough LE11 3TU, UK academic environments, has led to a rapid increase in the development of new approaches for both research [1-3] and education [4]. This increased access, as well as the iterative design process afforded by $3 \mathrm{D}$ printing, has resulted in design and print methodologies being made freely available to download from numerous open access online repositories [5-7]. This concept of open source hardware is now wellestablished across different academic disciplines [8], with the fabrication of 3D printed parts being utilised within chemical, pharmaceutical and biological environments, and consequently has been the subject of numerous review articles [9].

Within educational environments, academics have applied $3 \mathrm{D}$ printing to the manufacture of teaching aids, whereby $3 \mathrm{D}$ printed parts can provide a visual representation of educational material. This has been applied to the fabrication of 3D model kits that visualise molecular structures [10], orbitals and symmetry [11, 12], as well as 3D diagrams that represent spectroscopic data and energy profiles [13]. Around 30-40\% of school children are kinaesthetic learners [14], that is, they absorb information by engaging in physical activities as opposed to having information delivered to them in traditional learning environments such as lectures. 3D printing can be considered a kinaesthetic pedagogical tool for teaching complex concepts to this subset of learners. By participating in the 
manufacture and assembly of learning resources, students may engage more thoroughly in their application by tackling problems from a more holistic approach.

Numerous functional 3D printed devices have been developed for practical application in both research and undergraduate teaching laboratories such as low-cost syringe pumps [15, 16]. Various other printable components can be used to demonstrate the basic principles behind flow chemistry and fluid dynamics $[17,18]$. Such devices allow for innovative flow experiments to be made accessible to both college and undergraduate students at a low cost that aid teaching of concepts such as flow profile and mixing. Incorporating 3D printed teaching aids and laboratory hardware into chemical education has been the subject of a review article [19].

In this work, we present a step-by-step design workflow for developing a 'toolkit' of 3D printable fluidics components. The toolkit consists of six common fittings and connectors that are vital for re-configurable continuous flow set-ups. Three printable test boards have been designed to accompany the toolkit that allow users to bypass lengthy and laborious iterative modelling processes should the parts require adjustments to accommodate the use of alternative printers or materials.

A quick and easy alternative to computer aided design (CAD) 3D modelling has also been demonstrated for designing and customising a bespoke printable fluidics reactor chip using the user-friendly graphical interface of 3D modelling platform - Rhino 3D. The programme allows users to adjust channel dimensions and thread profiles of a fluidic reactor architectures for quick and easy design iteration.

The toolkit components and reactor chips themselves are to be used in conjunction with tubing to allow for students to design and modify their own systems potentially based on a given set of criteria such as residence time, flow profile etc. Using the toolkit components will allow students to develop a deeper understanding of small-scale fluid dynamics by observing the cause and effect relationship between system design and flow profile.

The toolkit consists of six parts; a standard 1/4"-28 Unified National Fine (UNF) thread Flat-Bottom, Flangeless Male Nut [20], a Low-Pressure Union [21, 22], a T Connector $[23,24], Y$ connector $[25,26]$ and Cross connector [27, 28] with 0.039" Channel bores and Flat Bottom female threads, and a Threaded Luer Adapter [29, 30], 0.039" channel bore, Female Luer x Female 1/4"-28 UNF Flat Bottom thread. Additional test boards used to optimize print dimensions for both the male [31] and female [32] threads and small feature limitations [33] are also included within the toolkit. These designs will be freely available and open source on Figshare [34]. The designs complement those that are commercially available, but also demonstrate the possibility of alternative geometries for alternative applications, as well as providing a means to mitigate the differences in print compatibility between different printers in different labs. The accessibility and low cost associated with the toolkit will allow flow chemistry to be introduced to undergraduate and college students earlier on in their education.

\section{Results and discussion}

\section{Design, Modelling and manufacture of a 3D printed fluidics toolkit}

Basic flow systems can be constructed by joining lengths of tubing together using screw fittings and connectors (Fig. 1). Systems can be easily re-configured by disconnecting screw fittings, replacing lengths of tubing and introducing additional junctions and connectors at various stages of a reaction. The configuration of a flow set up is vital for the outcome of a reaction. For example, early or late addition of materials to a multistage flow reaction can result in a low product yield or formation of unwanted side products.

Six main components considered vital for basic continuous flow configurations have been designed and modelled using 3D modelling software Siemens NX [35] (which is widely available to educational institutions and is also available for a free trial period. Other CAD modelling packages are also available including open source platforms such as OpenSCAD [36]). The parts we considered are derived from common pieces in use in flow chemistry laboratories around the world. These interconnects are required to provide a means to connect the pumping system to the flow tubing through a leak-free connection. By providing printable versions of these, we hope that these interconnections will be freely available, will provide a means to introduce $3 \mathrm{D}$ printing into the flow process, and generate inspiration for other, bespoke interconnection devices. The interconnects are a flangeless male nut which consisted of a male screw thread $\left(1 / 4^{\prime \prime}-28 \mathrm{UNF}\right)$ with a central channel bore (2.50 mm, Fig. 1a). The part is used for connecting tubing inlets and outlets of coiled flow reactors and lines of tubing to various junctions and mixers, the connection is made leak tight through the use of a ferule; a straight union (1/4"-28 UNF, Fig. 1b), used for unifying two separate lines of tubing; a T-piece ( $1 / 4 "-28$ UNF, Fig. 1c), for combining perpendicular flow streams; a cross-junction $(1 / 4 "-28$ UNF, Fig. 1d) for combining three flow streams into one; a Y-piece (1/4"-28 UNF, Fig. 1e), for combining two flow streams at a $120^{\circ}$ angle (typically used when laminar flow regimes are required) and a male Luer Lock to female $1 / 4^{\prime \prime}-$ $28 \mathrm{UNF}$ adapter (Fig. 1f), necessary for coupling a standard medical/laboratory grade Luer Lock plunger syringe to a line of tubing via a $1 / 4^{\prime \prime}-28$ UNF male nut. All connector pieces (Fig. 1b-e) can be substituted within a flow set up depending on the requirements of the reaction. For this study, Fused Deposition Modelling (FDM) has been used as a common, readily available printing process, however, other printing 
Fig. 1 3D printed toolkit components used in a basic flow configuration. a Male threaded nut. b Straight union. c Tconnector. d Cross connector. e Y-connector. f Luer adapter. g A flow configuration using the toolkit parts consisting of two syringe pumps each loaded with $5 \mathrm{~mL}$ plunger syringes connected to a water-heated coiled tubing rector via adapters and fittings, Luer assemblies outlined in blue, junction assembly outlined in red. h Assembly consisting of a plunger syringe coupled to a line of tubing via a Luer adapter and a male threaded nut. i Assembly consisting of two lines of inlet tubing combined into one outlet via a T-connector and three male threaded nuts

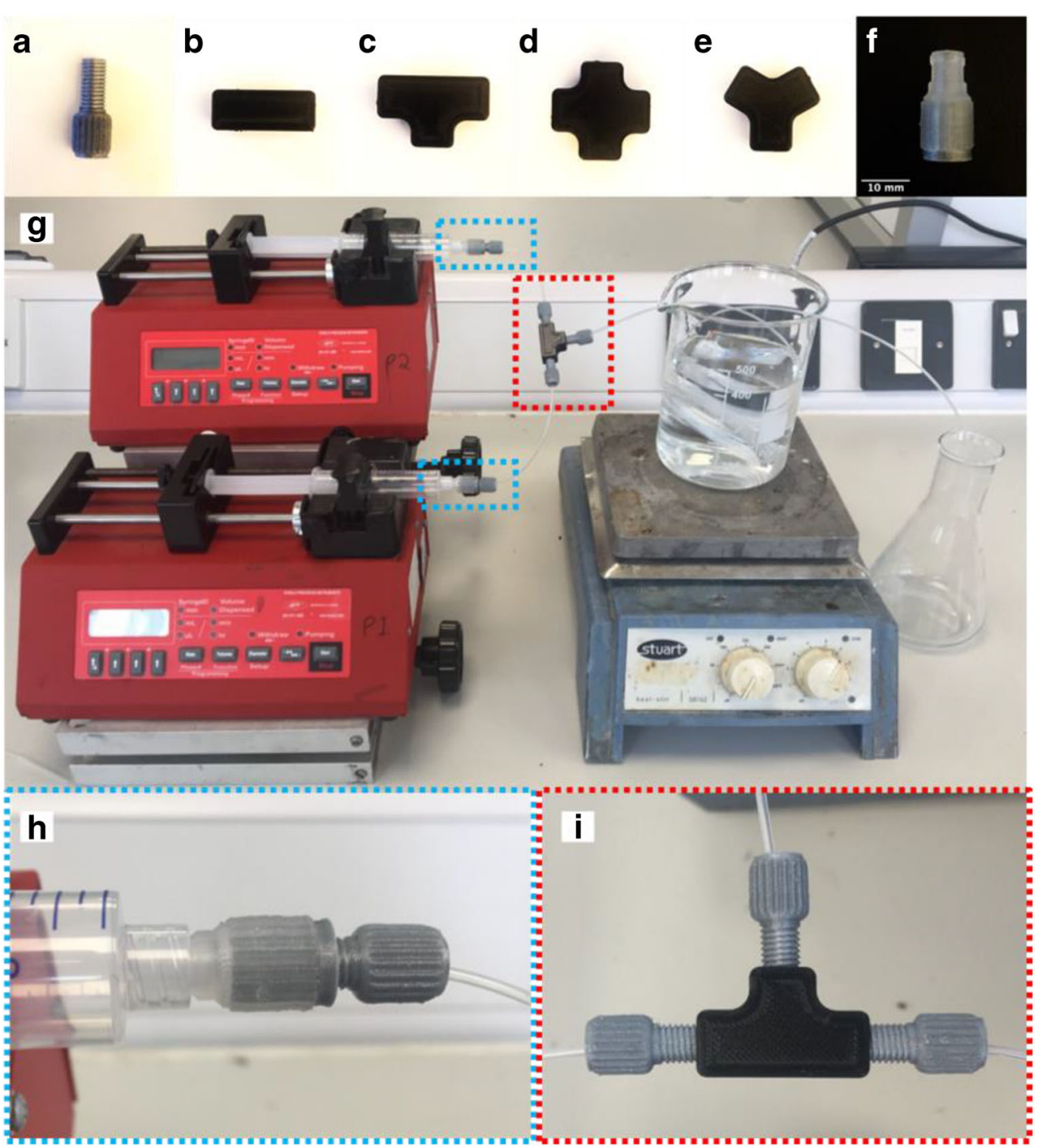

process such as Stereolithography (SL) and Selective Laser Melting (SLM) are available for printing with various other materials. Alternative printing processes may be used to manufacture the toolkit parts, however, the use of the printable test pieces included may be required to make dimensional adjustments to accommodate for differences in tolerances between processes and materials.

A basic flow configuration can be easily constructed using the toolkit parts and additional flow chemistry components such as tubing, plunger syringes, syringe pumps (or any other available fluid driving system), a heated water bath and a collection flask (Fig. 1g). The toolkit component dimensions have been standardized for part-to-part compatibility such that reliable, leak tight assemblies can be constructed (Fig. 1h-i).

The development of the 3D printed flow chemistry toolkit is described throughout the remainder this article in full detail. The resultant, open source part files are intended for download and "in-house" manufacture for use in practical demonstrations of continuous flow processing in both college and undergraduate laboratories. The low cost and accessibility of the toolkit will allow for entire classes of students to work independently on their own flow chemistry configurations. By participating in the development and manufacture of flow apparatus will also encourage students to engage more thoroughly in the component applications, and ultimately aid understanding of continuous flow processing.

Some of these components consisted of 'non-wetted' threads, that being, threaded features that do not come into direct contact with wet chemicals during their usage. Such parts required only structural rigidity, conversely, other 'wetted' components, which were intended to come into direct contact with wet chemicals during their usage, required both structural rigidity and resistance to common laboratory solvents at different regions. In the case of the latter, multimaterial 3D printing was used to combine multiple polymer properties into single units. 


\section{D printing of screw threads}

There is variability in the inherent capacity of $3 \mathrm{D}$ printing to replicate certain features of a part as most 3D printers have different tolerances in the $\mathrm{X}, \mathrm{Y}$ and $\mathrm{Z}$ plane. These tolerances can often be greater than the tolerances of some intricate part features, such as threaded regions. Dimensions of print outcomes can also subtly vary from the inputted CAD dimensions (Table 1) and selected print settings as a result of variations in environmental factors (e.g. room temperature, humidity), printer and material condition, as well as significant variability in print resolution when switching between different materials and printing instrumentation e.g. a thread printed in polypropylene will vary by several microns to the same thread printed from poly (lactic acid). These variations could be the difference between a successful or a failed printed part. It is therefore necessary to design and develop threads that are optimized for each unique instrumentation/material combination, as well as providing flexibility of design to account for any unwanted print variability. To demonstrate how to achieve this, a common commercial $1 / 4^{\prime \prime}-28$ UNF standard male threaded nut and its female counterpart have been modelled for reliable and consistent printing. This methodology has been structured so that it can be easily replicated for different parts, printers and materials.

\section{D printed male threaded Nut}

Within the thread feature box of the CAD modelling software, five dimensions were required; thread length, major diameter, minor diameter, pitch and angle (Fig. 2). These values were measured and averaged from five identical standard poly (etheretherketone) (PEEK) 1/4"-28 UNF flat-bottom, flangeless male nuts. The nuts were photographed, and their dimensions measured against a $10 \mathrm{~mm}$ reference scalebar (Table 2) using the National Institute of Health (NIH) open source image processing software, image $\mathrm{J}$.

A thread test board was modelled (Fig. 3a) that consisted of five threads based on the averaged commercial PEEK $1 / 4^{\prime \prime}-28$ UNF male thread profiles. The pitch, angle and length remain constant between threads (Table 2) and successive increases of $0.2 \mathrm{~mm}$ of both the major and minor diameters occurred between test threads 1-5 (Table 1). The test board has been made freely available on Figshare and can be printed and used as a starting point to determine the optimum thread dimensions for printing male threaded nuts that are compatible with $1 / 4^{\prime \prime}-28$ UNF female threads tailored for the users unique printing conditions and environment.

An important parameter to consider when printing any component, is the orientation of the part during the build; FDM 3D printers provide different surface resolutions in different directions. This is a product of the printer mechanics. Print resolution in the Z-direction is determined by the minimum optional layer height (that is, the dropping distance of the build plate between layers determined by the stepper motor resolution), and print resolution in the $\mathrm{X}, \mathrm{Y}$ direction is mainly restricted to the diameter of the extruder nozzle which directly affects the extent of die swelling (radial release of elastically stored energy within the polymer melt as it is liberated from the extruder nozzle) experienced by the polymer [37]. The extent of die swelling will affect the dimensions of the polymer bead size. Any feature of a print that is below the dimensions of the bead size will not fully resolve.

The minimum layer height provided by the Ultimaker 3 was $0.1 \mathrm{~mm}$ and minimum nozzle diameter available during the study was $0.4 \mathrm{~mm}$ (although, smaller nozzle sizes are available). Screw threads oriented in the X,Y direction (Fig. $3 d)$ were therefore of lower surface resolution than those printed in the Z-direction (Fig. 3e), the sharper thread teeth obtained by an upright print orientation further reduced the possibility of grip slippage upon tightening. Additionally, the orientation of a part determines the whereabout of support structures generated by the slicing software, an ideal screw thread should be free of any residual support material. The orientation of the part will also affect its mechanical properties. As FDM 3D printing is a layer by layer fabrication method, delamination can occur at certain points along the Z-axis. (i.e. a thread printed upright, in the Z-direction is most likely to experience delamination in between the thread teeth). The toolkit components were not designed to be used under excessive force; therefore, this was not considered to be an issue. An upright print orientation was chosen to obtain sharper thread teeth with minimal surface defects.

For this study, test thread No. 3 was considered the optimum set of dimensions. This was determined by pairing each test thread with a commercial PEEK 1/4"-28 UNF female thread and observing the amount of physical resistance
Table 1 Thread dimensions used for $1 / 4^{\prime \prime}-28$ male nut test board and subsequent measured values

\begin{tabular}{|c|c|c|c|c|c|c|c|c|c|c|}
\hline \multirow[t]{2}{*}{ Dimension } & \multicolumn{2}{|l|}{1} & \multicolumn{2}{|l|}{2} & \multicolumn{2}{|l|}{3} & \multicolumn{2}{|l|}{4} & \multicolumn{2}{|l|}{5} \\
\hline & $\mathrm{CAD}$ & Print & CAD & Print & $\mathrm{CAD}$ & Print & CAD & Print & CAD & Print \\
\hline Major diameter $(\mathrm{mm})$ & 5.86 & 5.82 & 6.06 & 5.83 & 6.26 & 5.88 & 6.46 & 6.19 & 6.66 & 6.68 \\
\hline Minor diameter (mm) & 4.76 & 4.97 & 4.96 & 4.99 & 5.16 & 5.11 & 5.36 & 5.35 & 5.56 & 5.84 \\
\hline
\end{tabular}


Table 2 Averaged dimensions of five $1 / 4$ "-28 UNF PEEK screw threads (imputed into CAD model) and dimensions measured from the resultant print out

\begin{tabular}{llll}
\hline Dimension & Measurement (CAD) & Measurement (Print) & Total Variation (\%) \\
\hline Length (mm) & 12.0 & 12.0 & 0.0 \\
Major Diameter $(\mathrm{mm})$ & 6.26 & 5.88 & -6.1 \\
Minor Diameter $(\mathrm{mm})$ & 5.16 & 5.11 & -1.0 \\
Pitch $(\mathrm{mm})$ & 0.91 & 0.91 & 0.0 \\
Angle $\left({ }^{\circ}\right)$ & 71.5 & 85.0 & 18.9 \\
\hline
\end{tabular}

experienced with each paring. When the variable diameters were too large then too much resistance was observed and thus a build-up of friction resulted in an incomplete thread mating. Conversely, when variable diameters were too narrow then too little resistance was experienced which resulted in grip slippage.

An initial nut was modelled (Fig. 3b-c) using the dimensions of the test board thread No. 3 (Table 1). The part was printed from PLA filament as the material has a high flexural modulus (the applied force up to which a material can resist bending) of $3150 \mathrm{MPa}$ at $23^{\circ} \mathrm{C}$ and is therefore resistant to bending at room temperature. This is an important property for a nut, as flexible thread teeth can result in slippage upon tightening. The printed male nut was completed by removing a central channel of $2.50 \mathrm{~mm}$ from the 3D model for the insertion of reactor tubing. A truncated cone was also negatively extruded into the head of the model to allow for the housing of a ferule, necessary to achieve a tight seal with component counterparts (Fig. 3f).

\section{D printed female threaded Nut}

The connector pieces included in the flow chemistry toolkit all required multiple female threaded channel inlets and outlets. For the union, cross, $\mathrm{T}$ and $\mathrm{Y}$ connectors, a horizontal

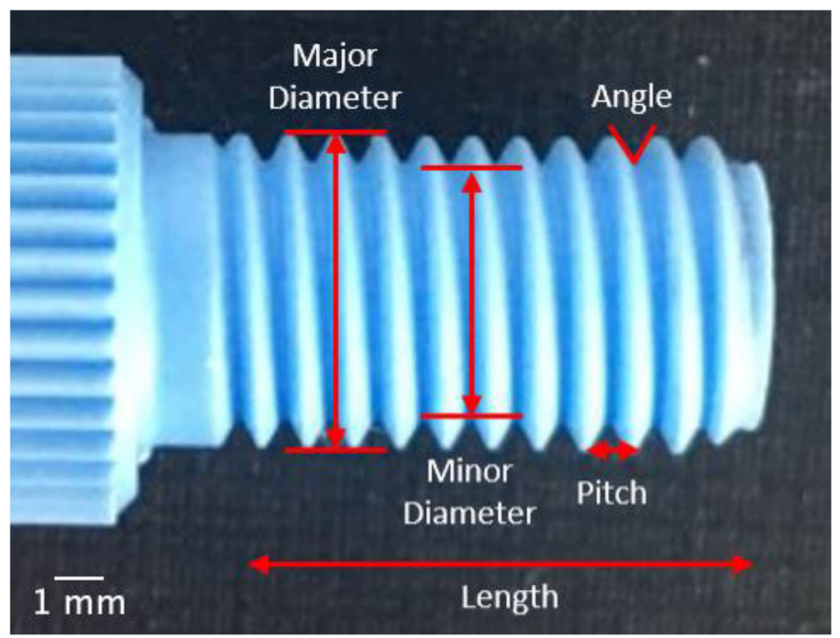

Fig. 2 Annotated thread of a $1 / 4^{\prime \prime}-28$ UNF, PEEK, flangeless male nut highlighting major and minor diameters, pitch, length and angle regions of a commercial PEEK male threaded nut orientation was required to achieve consistent print resolution across each thread, therefore the embodied threads were all printed in the $\mathrm{X}, \mathrm{Y}$ direction.

As variation in print geometries had previously been observed, it was decided that a printed thread dimension test board was again neccesary to optimise this geometry to acheive a tailored fit with the already printed male threaded nut. This allowed for part-to-part compatability between components.

A second test board was therefore modelled that consisted of four separate threaded channels (Fig. 4). Both the thread pitch and angle remained constant (Table 2). A shorter thread length of $8.00 \mathrm{~mm}$ was used to give a slight overhand allowing for variable tightening, and successive increases of $0.2 \mathrm{~mm}$ of both the major and minor diameters occurred between test threads 1-4 (Table 3 ).

Upon assessment, it was found that female thread No. 2 was the only thread on the test board that was compatible with both commercial PEEK and 3D printed 1/4"-28 UNF male threaded nuts. Thread No. 1 was compatible with the $3 \mathrm{D}$ printed nut, but too narrow for the commercial PEEK nut and thread No. 3 was compatible with the commercial PEEK nut, but too wide for the 3D printed nut. This difference was expected as the printed male nut was found to be slightly narrower in both major and minor diameters than the measured dimensions of the original commercial PEEK male nut from which it was modelled.

The resulting print dimensions of thread No. 2 also deviated from the inputted CAD dimensions, with the measured major diameter decreasing by $0.48 \mathrm{~mm}$, and the minor diameter increasing by $0.20 \mathrm{~mm}$. The female thread dimensions (Table 4) are used for integrated female threads throughout the remainder this article.

\section{D printing of wetted components}

As the housings and threaded regions of most flow components remain non-wetted during usage, the primary material selection criteria throughout the above sections has focused on mechanical properties. However, when planning for the fabrication of wetted regions such as flow channel walls, chemical properties e.g. inert materials with high resistance to laboratory solvents, were considered a priority. 
Fig. 3 Design profile of the 3D printed male threaded nut. a A $\mathrm{CAD}$ model of the flangeless male nut test board. b Annotated engineering drawing of male nut with thread dimensions $\mathbf{c}$ A CAD model of the finalised flangeless male nut $\mathbf{d} 3 \mathrm{D}$ printed thread printed in $\mathrm{X}, \mathrm{Y}$ orientation. $\mathrm{e}$ 3D printed thread printed in $Z$ orientation. $\mathbf{f} \mathrm{A} C \mathrm{CAD}$ assembly of feruled tubing inserted within a cross-sectional model of the flangeless male nut

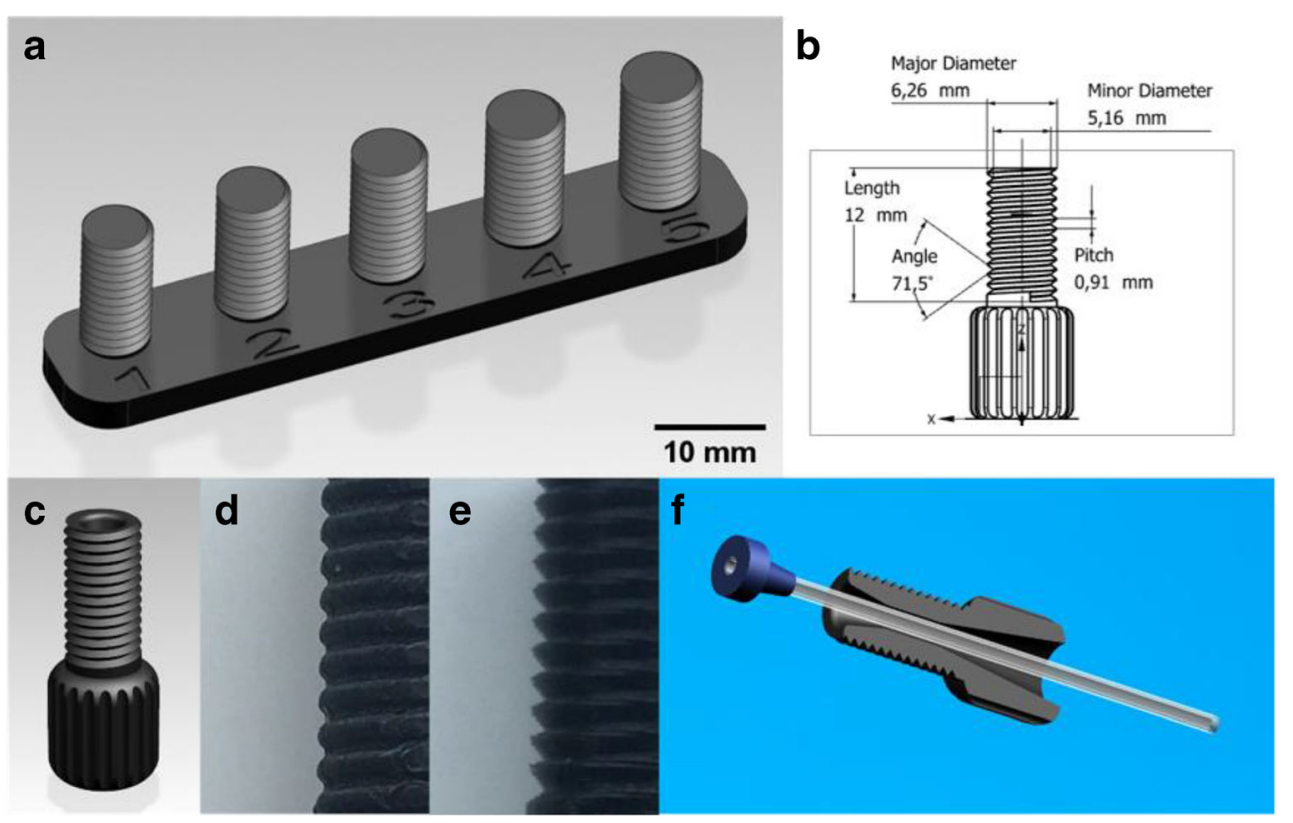

Commercial flow components are typically fabricated using PEEK in an injection moulding process. PEEK has a high tensile strength, flexural modulus, heat deflection temperature and is highly resistant to a wide range of laboratory solvents making it an ideal material for the fabrication of homogenous flow components. Although it is possible to $3 \mathrm{D}$ print using PEEK filament [38], as it currently stands, it is not a material that the most people have access to as its use requires specialist, high temperature printers. As affordable commercial 3D printers become more advanced, 3D printing with PEEK may in the future become more accessible. In the interim, Polypropylene (a well-known, chemically resistant hydrocarbon material) has been considered as an alternative common printing filament in place of PEEK to fabricate homogenous parts that exhibit both suitable mechanical strength and high solvent resistance.

\section{Solvent compatibility study}

When exposed to various classes of solvents for extended periods of time, layered polymeric materials can experience four modes of destruction at the solid-liquid interface, depending on the polymers affinity towards the solvent [39], these modes of destruction can be classed as disintegration, dissolution, delamination (the separation of polymer layers) and swelling. Swelling could cause a shrinkage in channel diameter, ultimately resulting in a blockage, and dissolution, disintegration and delamination could result in leakage. A $24 \mathrm{~h}$ solvent study was therefore carried out on identical PP sample cubes using an array of common laboratory solvents to reveal the extent of sample deformation. PLA was also included in the solvent study as a comparison (Table 5).

PLA showed unsatisfactory solvent compatibility ( $>2 \%$ size and/or wt. difference) on most of the solvent test pieces involved. Only alcohol, $5 \mathrm{M} \mathrm{HCL}$, water and hexane showed satisfactory compatibility $(<0.2 \%$ size and/or wt. difference), therefore concluding that PLA may be used to print only nonwetted regions of flow components. Polypropylene was found to show satisfactory solvent compatibility on most of solvent test pieces involved in the study with unsatisfactory compatibility only applying to ethers and both long chain and cyclic non-polar solvents. Both materials in the study showed clear visual destruction resulting from exposure to dichloromethane however PP did show satisfactory compatibility with chloroform.

\section{Mechanical strength of wetted flow components}

The mechanical strength of all flow fittings and connectors is a vital parameter to achieve robust, reliable connections
Table 3 Thread dimensions used for $1 / 4^{\prime \prime}-28$ UNF female nut test board and subsequent measured values

\begin{tabular}{lllllllll}
\hline Dimension & 1 & & 2 & & 3 & & 4 \\
& CAD & Print & CAD & Print & CAD & Print & CAD & Print \\
\hline Major Diameter $(\mathrm{mm})$ & 6.46 & 5.93 & 6.66 & 6.18 & 6.86 & 6.31 & 7.06 & 6.52 \\
Minor Diameter $(\mathrm{mm})$ & 5.36 & 5.60 & 5.56 & 5.76 & 5.76 & 5.93 & 5.96 & 6.10 \\
\hline
\end{tabular}


Fig. 4 a CAD model of $1 / 4^{\prime \prime}-28$ UNF female thread test board. $\mathbf{b}$ Resulting cross-sectional print of test board, optimum thread circled in red, the part was obtained by aborting the print at half-height. c Annotated engineering drawing of finalized female thread with thread dimensions
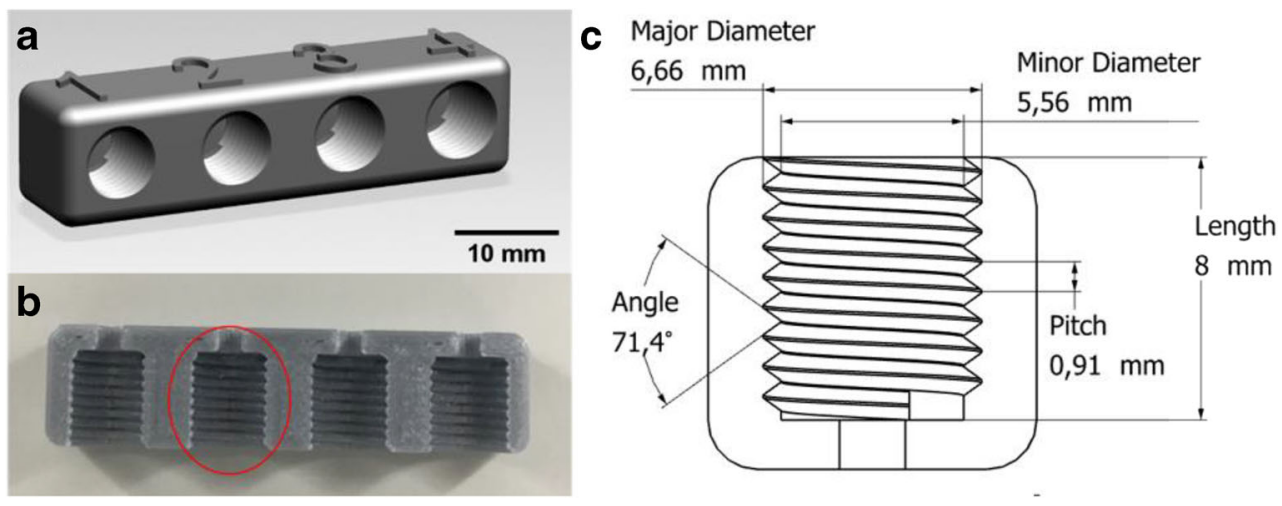

between parts. Inadequate mechanical properties are likely to result in failure to thread in the form of slippage or mechanical fracture. It was concluded that PLA was a suitable material for printing standard male nuts due to its high flexural modulus and non-wetted functionality but was proven unsuitable for the fabrication of wetted components due to its unsatisfactory solvent compatibility. Therefore, for printing homogenous, suitably solvent resistant, wetted components, with comparable performance to commercial PEEK parts, the mechanical properties of PP required examination.

Both the $1 / 4 "-28$ UNF flat-bottom flangeless male nut and the $1 / 4^{\prime \prime}-28$ UNF flat-bottom female nut were printed from PP using the CAD dimensions previously reported (Table 2 and Table 4 respectively).

Polypropylene has a low flexural modulus of $350 \mathrm{MPa}$, which caused bending of the thread teeth to occur upon use, even at low force. This specific material was therefore deemed inadequate for printing mechanically reliable threaded regions of the toolkit components. Laboratory usage of the resulting parts would likely result in excessive leaking at atmospheric conditions; however, it may be possible to subtly adjust these properties (i.e. with composite materials or subunit repetition) to overcome this limitation.

It was concluded that, although proven to be reasonably stable in a variety of solvents PP, for this formulation, was an unsuitable material for printing homogenous, wetted flow components that exhibited both resistance to common laboratory solvents, and suitable mechanical reliability. It was therefore proposed that multi material 3D printing could be used by utilizing the Ultimaker 3's dual extrusion functionality to combine the material properties of PLA and PP into one solid structure.

\section{Multi-material printing of composite flow components}

Multi material 3D printing (MM3DP) describes the process of additively manufacturing structures composed of more than one filament material. MM3DP is achievable using specialist FDM printers that are equipped with multiple extrusion nozzles that alternate their functioning with each layer. MM3DP has many numerous applications regarding the combination of material properties on single parts. Examples include structures with water soluble, dissolvable supports, to allow for greater design freedom and a smoother surface finish, multicoloured models and rigid structures with flexible regions (i.e. hinged boxes). These parts can be fabricated in one single print process and require no post print assembly. The Ultimaker 3 is such a printer that consists of two separate extrusion nozzles within one print head therefore allowing for multi material printing to be employed. It was proposed that this feature could be utilized to develop composite flow components that exhibited a rigid, threaded PLA non-wetted shell that housed a wetted chemically resistant PP core consisting of the flow channels.

\section{Core material print resolution}

The print resolution is a complex relationship that is determined by numerous variables including atmospheric
Table 4 List of $1 / 4^{\prime \prime}-28$ UNF optimized female thread dimensions for horizontal print orientation using PLA

\begin{tabular}{llll}
\hline Dimension & Measurement (CAD) & Measurement (Print) & Total Variation (\%) \\
\hline Length $(\mathrm{mm})$ & 8.00 & 8.37 & 4.6 \\
Major Diameter $(\mathrm{mm})$ & 6.66 & 6.18 & -7.2 \\
Minor Diameter $(\mathrm{mm})$ & 5.56 & 5.76 & 3.6 \\
Pitch $(\mathrm{mm})$ & 0.91 & 0.91 & 0.0 \\
Angle $\left({ }^{\circ}\right)$ & 71.4 & 77.2 & 8.1 \\
\hline
\end{tabular}


Table 5 Results of solvent effects on printable polymers, colours indicate varying degree of resistance, tick $(\checkmark)$ : Satisfactory compatibility $(<0.2 \%$ size and/or wt. difference), cross ( $\boldsymbol{X})$ : unsatisfactory compatibility ( $>2 \%$ size and/or wt. difference)

\begin{tabular}{lcc}
\hline Solvent & PLA & PP \\
\hline Acetone & $x$ & $\checkmark$ \\
Acetonitrile & $x$ & $\checkmark$ \\
Dimethyl sulfoxide & $x$ & $\checkmark$ \\
Ethanol & $\checkmark$ & $\checkmark$ \\
Methanol & $\checkmark$ & $\checkmark$ \\
2-Propanol & $\checkmark$ & $\checkmark$ \\
Diethyl ether & $x$ & $x$ \\
Tetrahydrofuran & $x$ & $x$ \\
Chloroform & $x$ & $\checkmark$ \\
Dichloromethane & $x$ & $x$ \\
Hexane & $\checkmark$ & $x$ \\
Toluene & $x$ & $x$ \\
Ethyl acetate & $x$ & $\checkmark$ \\
N,N-Dimethylformamide & $x$ & $\checkmark$ \\
5 M Hydrochloric acid & $\checkmark$ & $\checkmark$ \\
5 M Sodium hydroxide & $x$ & $\checkmark$ \\
Water & $\checkmark$ & $\checkmark$ \\
\hline
\end{tabular}

conditions, material selection, printer condition and calibration, and instrumentation limitations e.g. layer height and nozzle diameter. Significant variations in print resolution can also occur between different print materials. The $\mathrm{X}, \mathrm{Y}$ and $\mathrm{Z}$ resolution limitations of a printer are vital in determining the minimum feature sizes possible for print geometries. Therefore, when manufacturing intricate geometries, it is important to assess the theoretical resolution of new material/printer combinations.

Commercial fittings, like those presented in the toolkit, embody channel bores down to 0.020 " although other parts with various I.D.s are available to suit the requirements of the users flow configuration. An assessment was therefore carried out to determine the narrowest available channel diameters that could be produced by PP. A range of simple positive and negative, internal and external structures were modelled onto the surface of a small test board (Fig. 5a-b). The test board was printed in PP (Fig. 5c) and each section was analysed via optical microscopy (Fig. 5d1-5). The core material print resolution test showed that printing in PP allowed for internal channels with an I. D of down to $600 \mu \mathrm{m}$, and internal channels in the Z-direction down to $1 \mathrm{~mm}$. The print resolution test board is freely available for download from Figshare.

\section{D printed connectors}

In their simplest terms, fluidic connectors are threaded polymer junctions that connect tubular reactor coils together to allow for re-configuration of continuous fluidic setups. Examples of such components are basic straight unions, Tconnectors, Y-connectors and cross junctions. A basic
$26 \times 10 \times 10 \mathrm{~mm}$ core: shell union part was modelled and printed (Fig. 6) based on the previously determined print material and part geometries (see Tables 1, 2, 3 and 4). The union consisted of a PLA shell with two $1 / 4^{\prime \prime}-28$ UNF female screw threads at either end which followed the optimized thread dimensions previously reported (Table 4). An internal cubic void of $10 \times 7 \times 7 \mathrm{~mm}$ was removed from the centre of the model for the polypropylene core to be printed. A separate core piece was modelled with the same dimensions as the shell void and with a $1 \mathrm{~mm}$ diameter channel passing directly through the centre, before being unified into a single part with the shell within Ultimaker CURA slicing software.

The single unified model was raised $10 \mathrm{~mm}$ above the build plate to allow for the generation of a breakaway support scaffold. When printing with multiple filaments, the printer is programmed to heat the build plate to the highest of the two materials glass transition temperatures ( $\mathrm{Tg}$ ). In this case, the $\mathrm{Tg}$ of polypropylene at $85^{\circ} \mathrm{C}$ was $15^{\circ} \mathrm{C}$ higher than the $\mathrm{Tg}$ of PLA. Incorporating a $10 \mathrm{~mm}$ scaffold support structure below the raised part allowed for the dissipation of excess heat which prevented the PLA shell from warping.

The union connector was required to not only be resistant to solvent effects, but also dense enough to maintain liquid flow at elevated pressures without leaking. A leak test was carried out by flowing water through the part at $1 \mathrm{~mL} / \mathrm{min}$ at 1 bar pressure. It was immediately found that the inter-layer boundary of the PP core channel was insufficient to create liquid-tight seals. It was proposed that this may be overcome by increasing the extrusion or material flow rate of PP by $10 \%$, this was achieved by inputting the new flow rate value of $110 \%$ into the print settings within the CURA slicing software. The excess force used to feed the filament through the nozzle resulted in a 'squashed' polymer bead vacating the extrusion nozzle, this was done in an attempt to emulate the function of the Dolomite Microfluidics Fluidic Factory - an FDM 3D printer dedicated to creating sealed 3D microfluidic devices [40]. Increasing the extrusion rate of a material provides a larger contact area between set layers and thus reduces the possibility of leak paths forming by achieving a solid, homogenous part. A re-print was attempted with a PP extrusion flow rate of $110 \%$, although this was successful in preventing leakage occurring between laminated wall layers, leakage was still observed between the female and male thread connections. This was caused by insufficient contact forming between the polypropylene core and each of the ferules.

Achieving a leak tight seal between the ferule and the printed core was accomplished by modelling a new core structure that included two $1 \mathrm{~mm}$ positive ring extrusions surrounding the core channel inlet and outlet (Fig. 6a-c). By exploiting the elastic properties of PP, it was possible to create a compressible zone between the printed core and the ferule, effectively simulating a silicone O-ring. 

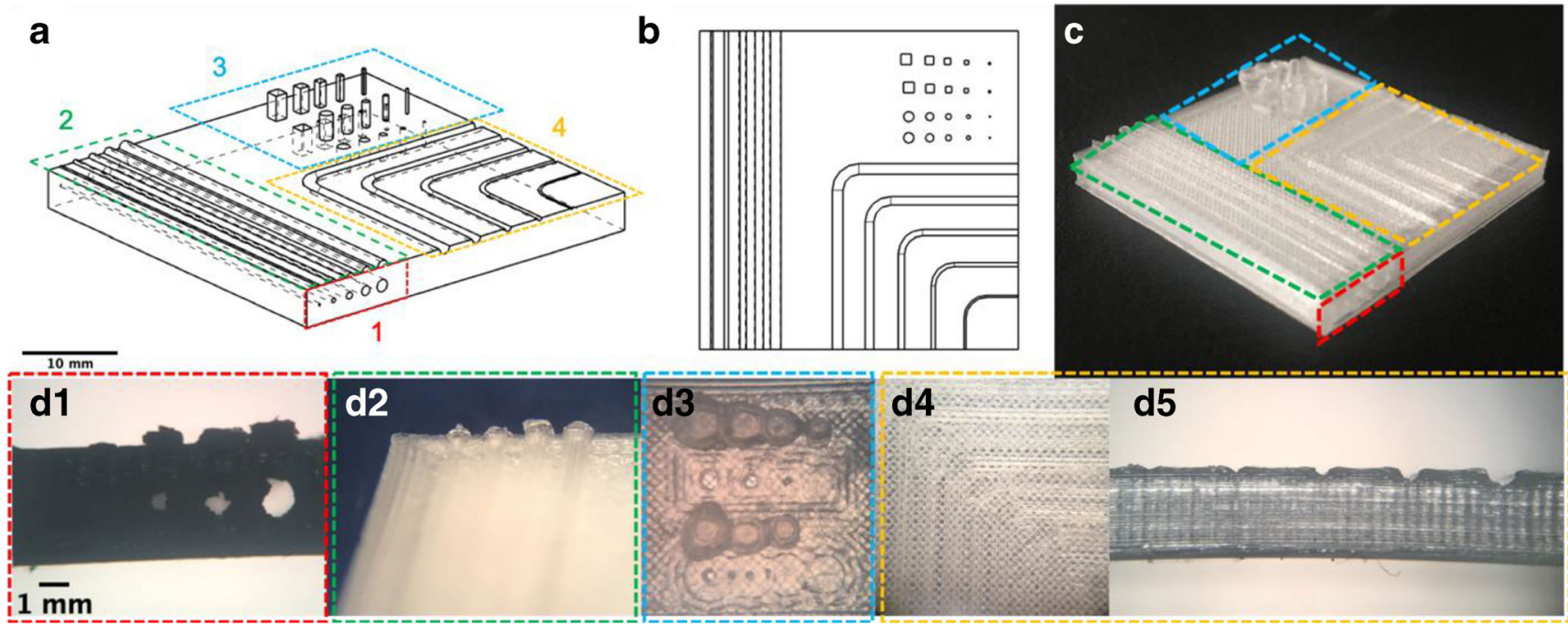

d4

d5

Fig. 5 a CAD engineering drawing of print resolution test board highlighting four regions of study, 1) Internal channels in $X, Y$ direction, 2) Positive, linear extrusions in $\mathrm{X}, \mathrm{Y}$ direction, 3) Positive and negative rounded and squared extrusions in Z-direction. 4) $90^{\circ}$ negative extrusions in $\mathrm{X}, \mathrm{Y}$ direction. b Top view image of resolution test board engineering drawing. $\mathbf{c}$ Image of PP print out of test board. d1-d5 Images of test board features of PP print taken by optical microscopy, colour coded with outlined regions in image a
The resultant part was leak tested and found to be functional up to a pressure of 53 bar at which point the tubing was forced out of the ferule, however no leaking around the union was observed.

The remaining three basic connectors and mixers considered necessary for a flow set up were modelled and printed (Fig. 7) using the parameters and design principles defined in the above sections. These remaining parts consisted of a PP: PLA (core: shell) low-pressure T-piece used for the
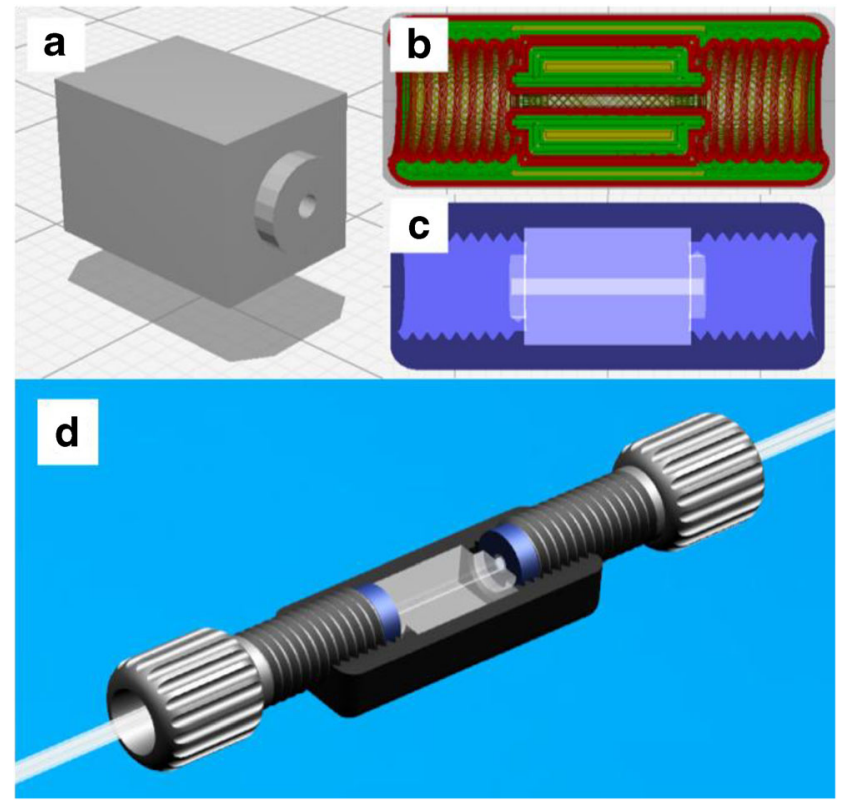

Fig. 6 a 3D model of leak tight core design including extruded channel O-rings. b Sliced layer view of combined shell and core models highlighting the positioning of the core extrusions. $\mathbf{c}$ X-ray view of sliced core shell union combined models. d CAD assembly of core: shell union cross-section with feruled $1 / 4^{\prime \prime}-28$ male nuts and tubing inserts perpendicular combining of two flow streams (Fig. 7b), a cross connector used for combining three flow streams at $90^{\circ}$ angles (Fig. 7c), and a Y-piece for combining two flow streams at $120^{\circ}$ angles (Fig. 7d). All parts consisted of $0.039^{\prime \prime}$ channel bores and flat bottom female threads modelled from the CAD dimensions previously demonstrated (Table 4). All parts were stable up to 53 bar pressure and showed no signs of leakage.

\section{D printed Luer adapter}

A Luer taper describes the standardized thread-like connections that allow the unification of fluidic devices often found in medical or laboratory environments to their mating counterparts. In basic flow chemistry configurations, female Luer threads are most found at the tip of Luer Lock syringes used to hold reagent reservoirs. Charged syringes are loaded into syringe pumps that regulate the discharge of solutions and drive flow streams through a channelled network. A vital component involved in this network is a Luer adapter which allows for the coupling of a threaded male nut to the outlet of a Luer Lock syringe. To complete the flow chem toolbox, it was clear that a Luer adapter was a key component that required a printable model.

Initial attempts at printing a core: shell Luer adapter design (Fig. 8a) resulted in failure to print a clear channel bore. The over extrusion of PP used to seal inter-layer wall boundaries caused the channel void to become filled with excess polymer during the print of the intricate, small core architecture. A revised structure was modelled which deviated from the original core: shell design and encompassed a PLA threaded region within fully PP Luer adapter architecture (Fig. 8b). By 


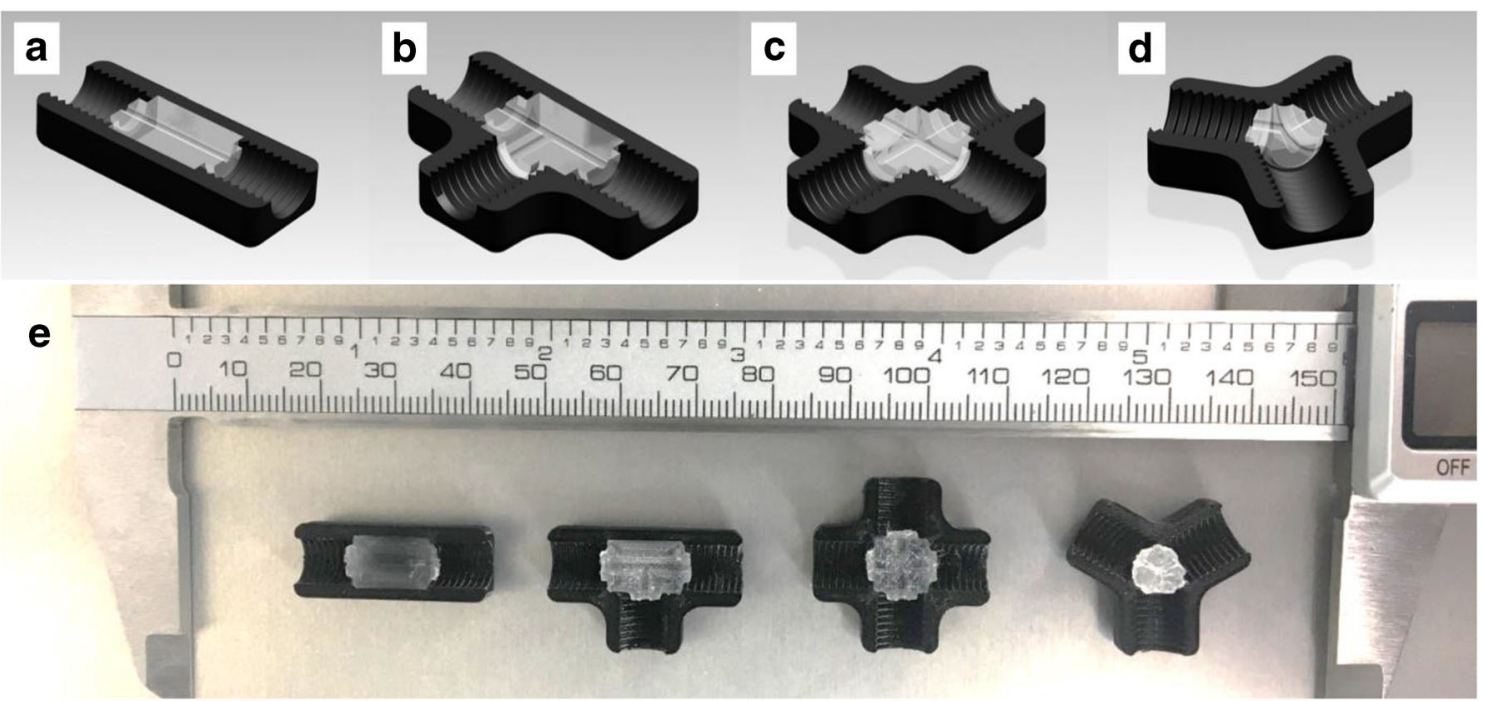

Fig. 7 3D cross-sectional models of all combined core: shell connectors. a Union. b T-piece. c Cross connector. d Y-piece. e Resulting cross-sectional prints of all toolkit connector parts

including a predominantly PP material composition into the design, any excess polymer was consumed during printing of the bulk body of the model and therefore was not present to seal the channel bore.

Standard syringes are restricted to operating at low pressures only. Operating at pressures over 1 bar can result in the syringe plunger collapsing, or the syringe pumps stalling. The part was however leak tested at 1 bar pressure by driving a stream of water $(1 \mathrm{~mL} / \mathrm{min}$ for $50 \mathrm{~min})$ through an assembly (Fig. 8c) consisting of a Luer Lock syringe coupled - via the 3D printed Luer adapter - to a feruled nut which housed a line
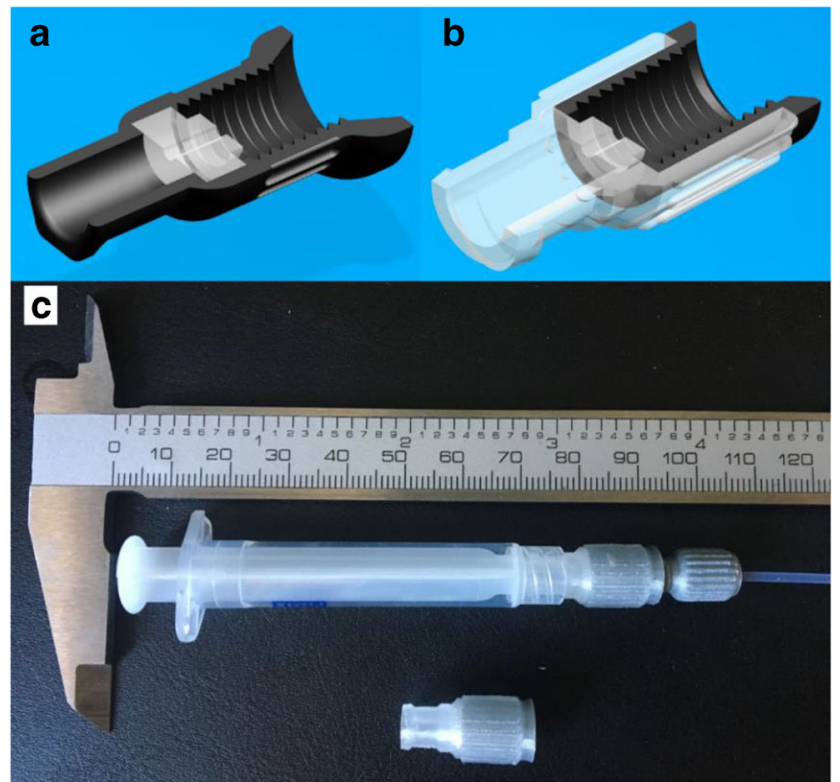

Fig. 8 a CAD cross-sectional image of initial PP (white, transparent): PLA (black), Core: Shell luer adapter. b CAD cross-sectional image of finalized PLA threaded, PP Luer adapter. $\mathbf{c}$ Photograph of 3D Printed finalized Luer adapter and Luer adapter assembly of reactor tubing. No leaking was observed under these operating conditions.

\section{Build times, material usage and cost}

Toolkit part costs were derived from the cost of both filament reels, subdivided into portions of spent material involved in manufacture of parts.

The total material usage for the entire 3D Printed fluidics toolkit was $25 \mathrm{~g}$ PLA and $<5 \mathrm{~g}$ PP. This amounts to a total sum of $£ 1.43$ of material used during printing, including all support scaffolds and adhesion brims. The total toolkit print time equated to $9 \mathrm{~h} 49 \mathrm{~min}$ (Table 6).

\section{D printed fluidic reactor Chip}

The flow chemistry configurations previously described throughout this article have centred around the use of coiled tubing as a reaction vessel, with the printed connectors allowing preparation of a fully functioning flow system. Recent years have seen significant advancements towards the use of fluidics chips as an alternative to coiled tube reactors [41]. In their simplest terms, fluidics chips are planar geometries with integrated flow channels that associate a channel inlet to a channel outlet. Most fluidics chips also contain integrated female threads for the coupling of connector tubing via standard fittings. Channel bends and turns can cause Dean vortices to occur at specific points of a flow stream which in turn, promotes mixing [42]. Using reactor chips as opposed to coiled tubing therefore offers the added advantage of standardizing channel geometries which, in turn, regulates mixing effects.

The manufacturing of fluidics chips requires intricate and costly methods, a high level of skill, and often, clean room 
Table 6 A list of print times and total material costs for all toolkit parts and their price comparisons to their original commercial parts

\begin{tabular}{|c|c|c|c|c|c|}
\hline Part & $\begin{array}{l}\text { Build time } \\
\text { (min) }\end{array}$ & $\begin{array}{l}\text { Material usage - } \\
\text { PLA (g) }\end{array}$ & $\begin{array}{l}\text { Material usage - } \\
\text { PP (g) }\end{array}$ & $\begin{array}{l}\text { 3DP Part } \\
\text { Cost }(\mathfrak{£})\end{array}$ & $\begin{array}{l}\text { Commercial part } \\
\text { cost }(£)\end{array}$ \\
\hline $\begin{array}{c}\text { Flangeless Male } \\
\text { Nut }(\times 10)\end{array}$ & 240 & 10 & N/A & 0.52 & 33.36 \\
\hline Union & 67 & 3 & 1 & 0.19 & 14.65 \\
\hline Tee - junction & 83 & 4 & 1 & 0.23 & 30.58 \\
\hline Cross - junction & 91 & 4 & $<1$ & 0.22 & 27.52 \\
\hline Y - junction & 73 & 3 & $<1$ & 0.18 & 24.43 \\
\hline Luer adapter & 44 & 1 & 1 & 0.11 & 14.20 \\
\hline
\end{tabular}

environments which results in a high price associated with individual parts, for example glass chips. The advent of 3D printing, however, has afforded researchers the opportunity to design and manufacture their own fluidics chips in-house with user defined channel geometries and dimensions in a matter of hours and for a fraction of the price of commercial products [43-45].

As $3 \mathrm{D}$ printing technologies advance, it is believed that inhouse manufacturing of fluidics devices will become commonplace in the laboratory, it is therefore of upmost importance that such methods are introduced to students early on in their education. The use of 3D computer aided design software gives a high degree of design freedom but has a high barrier to entry on learning of different software. Moreover, for each design iteration, the design will need to be re-visited from scratch; a very time intensive task for a chemist who is initially unfamiliar with the software. As an alternative approach, and one which is more chemist-friendly, Rhino 3D [46] is a modelling platform that allows select features of an imported 3D model to be adjusted using parameter slider bars, the software package may be available to educational institutions, conversely, it is also available as a 90 day free trial evaluation from the supplier. A basic fluidic reactor chip [47] has been modelled and imported into Rhino 3D (Fig. 9a), the channel dimensions of which can be easily manipulated using the software interface to explore the effects of channel geometry on reaction outcome. The resulting model (Fig. 9b) can be used in combination with the described 3D printed toolkit of fittings and connectors to achieve a working continuous flow configuration (Fig. 9c-d).

\section{Modelling and printing a fluidic reactor Chip}

The code for the 3D model of a basic fluidic reactor chip was written using the modelling development platform Grasshopper (which included as a plug in within the Rhino 3D software package) and saved as a .gh file (available from Figshare). Once imported into Rhino 3D, the model could be visualised. The fluidic reactor consists of one adjustable
Fig. 9 a CAD model of fluidic reactor chip visualised in Rhino 3D. b 3D Printed polypropylene fluidic reactor chip created from rhino 3D model. c Example flow configuration with integrated fluidic reactor chip. d Close up image of fluidic reactor chip integrated with flow configuration

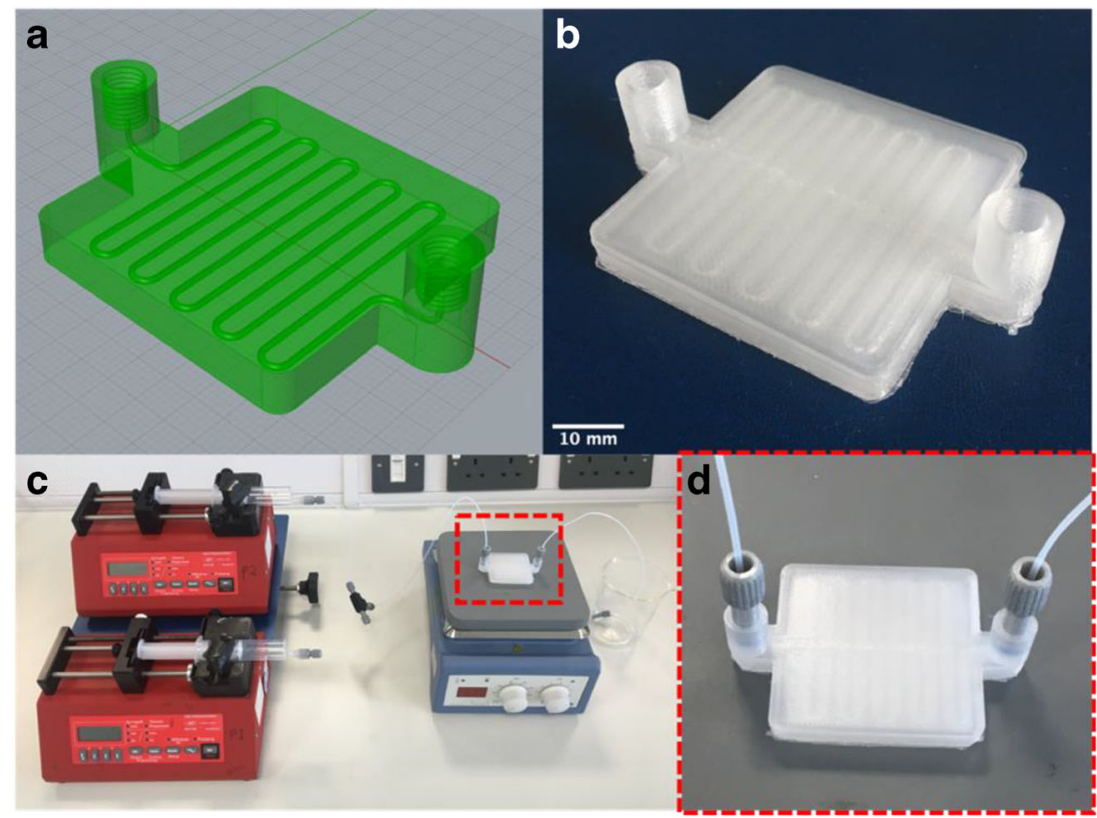


threaded inlet and outlet and a continuous serpentine channel geometry, the dimensions of which could be manipulated by altering each parameter value using slider bars within the programme's user interface (Fig. 10).

The recommended print material for the fluidic reactor chip when using FDM is PP with an increased material flow rate of $110 \%$, a layer height of $0.1 \mathrm{~mm}$ and an infill of $100 \%$. All other print settings should remain as factory default to achieve a leak tight print. Other printing processes (such as SL or SLM) may also be used to print the reactor chip where different feature sizes, or material properties may be required.

Once imported into Rhino 3D, both channel and thread dimensions can be easily adjusted to achieve variations upon the original model. When building a flow set-up this variation allows for a similar degree of freedom as when using coiled reactor tubing as channel length and radius can be user defined. Any adjustments made will affect the reactor volume which is calculated in real time within the programme and is displayed above parameter sliders. The 'pipe radius' slider adjusts the radius of the entire channel in mm, for PP (Fig. $10 \mathrm{a}$ ), it is recommended to stay above a radius of $0.6 \mathrm{~mm}$ when printing in PP with an Ultimaker 3. The 'pipe length' slider adjusts the length of each of the linear parallel regions of the serpentine structure and as a result, the footprint of the entire reactor chip (Fig. 10b) and the 'pipe Number' slider adjusts the number of connected linear parallel channels within the serpentine structure and therefore also impacts on the footprint of the chip (Fig. 10c).

Thread dimensions can also be adjusted within the programme. The thread dimensions have been optimized for PP using an Ultimaker 3 printer as: Nominal diameter $=6.76 \mathrm{~mm}$, Pitch $=0.9 \mathrm{~mm}$ and Number of turns $=8$. These settings will achieve thread profiles that are compatible with both commercial and $3 \mathrm{D}$ printed $1 / 4^{\prime \prime}-28$ UNF male threaded nuts, however, this feature can also be used to optimize female threads for alternative printer/material combinations, a procedure that when relying on CAD modelling alone - is often time consuming and requires undoing and repeating multiple stages.

Figure 10 illustrates a screenshot of the programme interface, with the reactor volume calculated as the sliders are moved to change the dimensions as indicted. This provides the chemist with an almost limitless number of reactor geometries to choose from, even on such a simple chip design. More intricate chips with multiple inlets/outlets could also be designed and used in such a manner. The video in the Supplementary Material illustrates the ease with which the chemist can interface with the software to see their design change in real time. This highly intuitive interface is much more user-friendly during the design phase of the reactor build.

On conclusion of the design, the part can be saved as a standard file type and exported for printing as normal. It can
Fig. 10 Screen shots of slider bar windows and corresponding models within Rhino 3D showing a largest possible channel diameter. b largest possible channel length. $\mathbf{c}$ largest possible channel number with their corresponding channel volumes

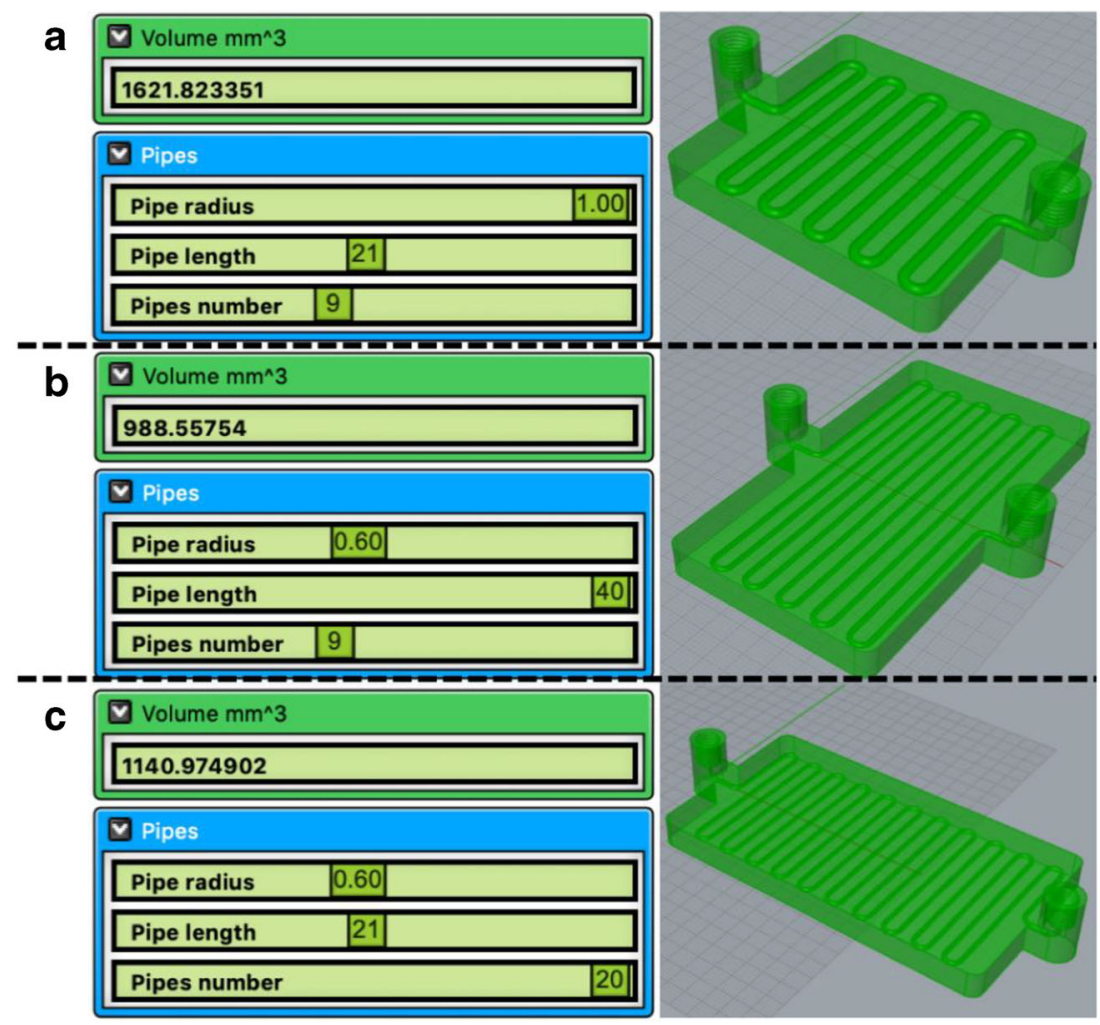


then be used directly in the flow reaction of choice, taking into consideration solvent and temperature compatibility of the chosen material.

\section{Conclusions}

In this article, we have demonstrated the development of a fully 3D printable flow chemistry toolkit which consists of the six necessary components required for constructing reconfigurable flow chemistry set ups along with test boards that allow for rapid optimization of male and female thread profiles tailored to the users printing conditions, materials and environment. A print resolution test board is also included within the toolkit for assessing internal and external print feature size limitations. Using the printable test boards significantly reduces the labour intensity involved in optimizing the dimensions of 3D printable fluidic components.

A quick and easy solution has also been provided for modelling and customising a bespoke fluidics reactor chip using the user-friendly graphical interface of modelling software - Rhino 3D. The software package eliminates the need for lengthy CAD design iterations that would otherwise be necessary for adjusting variable flow channel dimensions and thread profile parameters of a fluidic reactor chip.

The toolkit components themselves may be used as lowcost and accessible teaching resources to allow for both undergraduate and college students to be introduced to the principles of flow chemistry earlier on in their education. Providing students with the opportunity to manufacture and assemble their own flow configurations may encourage students to engage more thoroughly in the principles of flow chemistry, this particularly applies to kinaesthetic learners.

All toolkit parts, test boards and reactor chip files have been made available and open-source, individual part, .stl and .gh files can be downloaded from Figshare at no cost for direct use. The toolkit parts can be printed for a total material cost $£ 1.43$ over a printing period of $9 \mathrm{~h} 49 \mathrm{~min}$. Only PLA and PP filaments are required along with a dual extrusion FDM 3D printer. The Figshare online link to the parts will remain live for the addition of future components not discussed in this article.

\section{Materials and methods}

\section{Computer aided design, 3D printing and part processing}

CAD modelling was performed using Siemens NX [35], v11.0 and Rhino 3D [46], v6 software. Completed .stl files were processed using Ultimaker Cura, v4.5.0. Following the removal of parts from the build plate, post processing involved only the removal of breakaway support scaffolds and adhesion brims from the model by hand.

All parts were manufactured using an Ultimaker 3 desktop fused deposition modelling (FDM) 3D printer with dual extrusion capabilities. Polymer filaments used were Ultimaker $2.85 \mathrm{~mm}$ natural polypropylene (PP, RS Components, P/N 1785 ) and Ultimaker $2.85 \mathrm{~mm}$ black polylactic acid (PLA, RS Components, P/N 1609).

Additional equipment required during development was a $3 \mathrm{~mL}$ Norm-Ject ${ }^{\mathrm{TM}}$ Luer Lock plastic syringe (Restek, PN: 22773), polytetrafluoroethylene (PTFE) tubing 1/16" $(1.6 \mathrm{~mm}$ ) outside diameter $(\mathrm{OD}) \times 0.3 \mathrm{~mm}$ inside diameter (ID) (Kinesis, PN: 008 T16-030-20), and Idex P-200X flangeless ferrule, blue ethylene tetrafluoroethylene (ETFE), 1/16" OD tubing, $1 / 4^{\prime \prime}-28$ UNF flat-bottom (Cole-Parmer, PN: WZ-01939-30).

\section{Solvent compatibility and pressure testing}

$10 \times 10 \times 10 \mathrm{~mm}$ cubes were modelled, then printed flat in either PLA or PP on a $10 \mathrm{~mm}$ support. After removal from the support material, each cube was measured on two pairs of sides (avoiding the top/bottom pair due to deformation resulting from residual support material) with callipers then weighed. The weighed and measured cubes were then placed into glass sample vials containing $10 \mathrm{~mL}$ of the test solvent/reagent, the vials capped and allowed to sit for $24 \mathrm{~h}$. The treated cubes were removed from the solvent and allowed to dry in air for $24 \mathrm{~h}$ then reweighed and measured. The effect of each solvent/ reagent was tested in duplicate, and values for the four width measurements and two masses were averaged before and after exposure.

Pressure testing was carried out by connecting an AZURA ${ }^{\circledR}$ P4.12 high performance liquid chromatography (HPLC) pump with embedded pressure transducer to the inlets of each 3D printed fitting and connector using PTFE tubing. The outlets of each part were connected to a Vapourtec manually adjustable back pressure regulator (BPR). Water was flowed through the system at $1 \mathrm{~mL} / \mathrm{min}$ whilst the pressure was gradually increased until failure or observable leakage.

Funding The authors acknowledge funding from Loughborough University for this work.

\section{Compliance with ethical standards}

Declarations They declare no competing conflicts of interest. Data and code is made available for use in non-commercial work through the Figshare links in the main text and reference sections. Users must take due care to ensure any prints they prepare and use are of suitable quality and are fully tested before use in any chemistry application. 
Open Access This article is licensed under a Creative Commons Attribution 4.0 International License, which permits use, sharing, adaptation, distribution and reproduction in any medium or format, as long as you give appropriate credit to the original author(s) and the source, provide a link to the Creative Commons licence, and indicate if changes were made. The images or other third party material in this article are included in the article's Creative Commons licence, unless indicated otherwise in a credit line to the material. If material is not included in the article's Creative Commons licence and your intended use is not permitted by statutory regulation or exceeds the permitted use, you will need to obtain permission directly from the copyright holder. To view a copy of this licence, visit http://creativecommons.org/licenses/by/4.0/.

\section{References}

1. Khaled SA, Burley JC, Alexander MR, Roberts CJ (2014) Desktop $3 \mathrm{D}$ printing of controlled release pharmaceutical bilayer tablets. Int J Pharm 461:105-111. https://doi.org/10.1016/j.ijpharm.2013.11. 021

2. Gupta V, Beirne S, Nesterenko PN, Paull B (2018) Investigating the effect of column geometry on separation efficiency using $3 \mathrm{D}$ printed liquid chromatographic columns containing polymer monolithic phases. Anal Chem 90:1186-1194. https://doi.org/10.1021/ acs.analchem. $7 \mathrm{~b} 03778$

3. Azuaje J, Tubío CR, Escalante L, Gómez M, Guitián F, Coelho A, Caamaño O, Gil A, Sotelo E (2017) An efficient and recyclable 3D printed $\alpha$-A12O3catalyst for the multicomponent assembly of bioactive heterocycles. Appl Catal A Gen 530:203-210. https://doi. org/10.1016/j.apcata.2016.11.031

4. Hartings MR, Ahmed Z (2019) Chemistry from 3D printed objects. Nat Rev Chem 3:305-314. https://doi.org/10.1038/s41570-0190097-z

5. Thingiverse - Digital Designs for Physical Objects. https://www. thingiverse.com/. Accessed 23 Jun 2020

6. yeggi - 3D Printer Models Search Engine. https://www.yeggi.com/. Accessed 23 Jun 2020

7. NIH 3D Print Exchange $\mid$ A collection of biomedical 3D printable files and $3 \mathrm{D}$ printing resources supported by the National Institutes of Health (NIH). https://3dprint.nih.gov/. Accessed 23 Jun 2020

8. Pearce JM (2017) Impacts of open source hardware in science and engineering. Bridge 47:24-31

9. Capel AJ, Rimington RP, Lewis MP, Christie SDR (2018) 3D printing for chemical, pharmaceutical and biological applications. Nat Rev Chem. https://doi.org/10.1038/s41570-018-0058-y

10. Rossi S, Benaglia M, Brenna D, Porta R, Orlandi M (2015) Three dimensional (3D) printing: a straightforward, user-friendly protocol to convert virtual chemical models to real-life objects. J Chem Educ 92:1398-1401. https://doi.org/10.1021/acs.jchemed.5b00168

11. Scalfani VF, Vaid TP (2014) 3D printed molecules and extended solid models for teaching symmetry and point groups. J Chem Educ 91:1174-1180. https://doi.org/10.1021/ed400887t

12. Robertson MJ, Jorgensen WL (2015) Illustrating concepts in physical organic chemistry with 3D printed orbitals. J Chem Educ 92: 2113-2116. https://doi.org/10.1021/acs.jchemed.5b00682

13. Kaliakin DS, Zaari RR, Varganov SA (2015) 3D printed potential and free energy surfaces for teaching fundamental concepts in physical chemistry. 3-9. https://doi.org/10.1021/acs.jchemed.5b00409

14. Pourhosein Gilakjani A (2011) Visual, auditory, Kinaesthetic learning styles and their impacts on English language teaching. J Stud Educ 2:104. https://doi.org/10.5296/jse.v2i1.1007

15. Booeshaghi AS, da Veiga Beltrame E, Bannon D, Gehring J, Pachter L (2019) Principles of open source bioinstrumentation applied to the poseidon syringe pump system. Sci Rep 9:1-8. https://doi.org/10.1038/s41598-019-48815-9

16. Almada P, Pereira PM, Culley S, Caillol G, Boroni-Rueda F, Dix CL, Charras G, Baum B, Laine RF, Leterrier C, Henriques R (2019) Automating multimodal microscopy with NanoJ-fluidics. Nat Commun 10:1-9. https://doi.org/10.1038/s41467-019-09231-9

17. Tabassum T, Iloska M, Scuereb D, Taira N, Jin C, Zaitsev V, Afshar F, Kim T (2018) Development and application of 3D printed Mesoreactors in chemical engineering education. J Chem Educ 95: 783-790. https://doi.org/10.1021/acs.jchemed.7b00663

18. Vangunten MT, Walker UJ, Do HG, Knust KN (2020) 3D-printed microfluidics for hands-on undergraduate laboratory experiments. J Chem Educ 97:178-183. https://doi.org/10.1021/acs.jchemed. $9 \mathrm{~b} 00620$

19. Pinger CW, Geiger MK, Spence DM (2020) Applications of 3Dprinting for improving chemistry education. J Chem Educ 97:112117. https://doi.org/10.1021/acs.jchemed.9b00588

20. 3D Printed Male Threaded Nut. https://doi.org/10.17028/rd.lboro. 12613100.v1. Accessed 2 Aug 2020

21. Union Connector (CORE). https://doi.org/10.17028/rd.lboro. 12613118.v1. Accessed 2 Aug 2020

22. Union Connector (SHELL). https://doi.org/10.17028/rd.lboro. 12613124.v1. Accessed 2 Aug 2020

23. Tee Connector (CORE). https://doi.org/10.17028/rd.lboro. 12613127.v1. Accessed 2 Aug 2020

24. Tee Connector (SHELL). https://doi.org/10.17028/rd.lboro. 12613133.v1. Accessed 2 Aug 2020

25. Y Connector (CORE). https://doi.org/10.17028/rd.lboro.12613142. v1. Accessed 2 Aug 2020

26. Y Connector (SHELL). https://doi.org/10.17028/rd.lboro. 12613145.v1. Accessed 2 Aug 2020

27. Cross Connector (CORE). https://doi.org/10.17028/rd.lboro. 12613136.v1. Accessed 2 Aug 2020

28. Cross Connector (SHELL). https://doi.org/10.17028/rd.lboro. 12613139.v1. Accessed 2 Aug 2020

29. Luer Adapter (BODY). https://doi.org/10.17028/rd.lboro. 12613148.v1. Accessed 2 Aug 2020

30. Luer Adapter (INSERT). https://doi.org/10.17028/rd.lboro. 12613151.v1. Accessed 2 Aug 2020

31. Male Thread Test Board. https://doi.org/10.17028/rd.lboro. 12751730.v1. Accessed 2 Aug 2020

32. Female Thread Test Board. https://doi.org/10.17028/rd.lboro. 12751739.v1. Accessed 2 Aug 2020

33. Print Resolution Test Board. https://doi.org/10.17028/rd.lboro. 12751745.v1. Accessed 2 Aug 2020

34. 3D-Printed Fluidics Toolkit. https://repository.lboro.ac.uk/projects/ FDM_Fluidics_Tookit/84392. Accessed 6 Aug 2020

35. NX. https://www.plm.automation.siemens.com/global/en/ products/nx/. Accessed 6 Aug 2020

36. OpenSCAD - The Programmers Solid 3D CAD Modeller. https:// www.openscad.org/. Accessed 6 Aug 2020

37. Turner BN, Strong R, Gold SA (2014) A review of melt extrusion additive manufacturing processes: I. process design and modeling. Rapid Prototyp J 20:192-204. https://doi.org/10.1108/RPJ-012013-0012

38. Harding MJ, Brady S, O'Connor H, Lopez-Rodriguez R, Edwards MD, Tracy S, Dowling D, Gibson G, Girard KP, Ferguson S (2020) $3 \mathrm{D}$ printing of PEEK reactors for flow chemistry and continuous chemical processing. React Chem Eng 5:728-735. https://doi.org/ 10.1039/c9re00408d

39. Erokhin KS, Gordeev EG, Ananikov VP (2019) Revealing interactions of layered polymeric materials at solid-liquid interface for building solvent compatibility charts for $3 \mathrm{D}$ printing applications. Sci Rep 9:1-14. https://doi.org/10.1038/s41598-019-56350-w

40. Pranzo D, Larizza P, Filippini D, Percoco G (2018) Extrusionbased 3D printing of microfluidic devices for chemical and 
biomedical applications: a topical review. Micromachines 9: . https://doi.org/10.3390/mi9080374

41. Haswell SJ, Watts P (2003) Green chemistry: synthesis in micro reactors. Green Chem 5:240-249. https://doi.org/10.1039/ b210539j

42. Bettermann S, Kandelhard F, Moritz H, Pauer W (2019) Chemical engineering research and design digital and lean development method for 3D-printed reactors based on CAD modeling and CFD simulation. Chem Eng Res Des 152:71-84. https://doi.org/10.1016/j. cherd.2019.09.024

43. Capel AJ, Edmondson S, Christie SDR, Goodridge RD, Bibb RJ, Thurstans M (2013) Design and additive manufacture for flow chemistry. Lab Chip 13:4583-4590. https://doi.org/10.1039/ c3lc50844g

44. Dragone V, Sans V, Rosnes MH, Kitson PJ, Cronin L (2013) 3Dprinted devices for continuous-flow organic chemistry. Beilstein $\mathrm{J}$ Org Chem 9:951-959. https://doi.org/10.3762/bjoc.9.109
45. Rao ZX, Patel B, Monaco A, Cao ZJ, Barniol-Xicota M, Pichon E, Ladlow M, Hilton ST (2017) 3D-printed polypropylene continuous-flow column reactors: exploration of reactor utility in SNAr reactions and the synthesis of bicyclic and tetracyclic Heterocycles. Eur J Org Chem 2017:6499-6504. https://doi.org/ 10.1002/ejoc.201701111

46. Rhino 6 for Windows and Mac. https://www.rhino3d.com/. Accessed 6 Aug 2020

47. Fluidic reactor chip. https://doi.org/10.17028/rd.lboro.12765686. v1. Accessed 5 Aug 2020

Publisher's note Springer Nature remains neutral with regard to jurisdictional claims in published maps and institutional affiliations. 